\title{
Calcium handling in airway smooth muscle: Mechanisms and therapeutic implications
}

\author{
Luke J Janssen BSc MSc PhD \\ Asthma Research Group, Smooth Muscle Research Group, \\ Department of Medicine, McMaster University
}

\section{LJ Janssen. Calcium handling in airway smooth muscle: Mechanisms and therapeutic implications. Can Respir J 1998;5(6):491-498.}

Calcium plays a central role in the activation of many cellular processes, including the most relevant end-point in airway smooth muscle physiology: contraction. For this reason, the cytosolic concentration of calcium is tightly controlled by an elaborate array of mechanisms. The latter include multiple entry pathways from the extracellular space, a pump on the membrane that extrudes calcium out of the cell, an internal pump that sequesters calcium into an intracellular pool and at least two types of release sites from which sequestered calcium can be released back into the cytosol; all of these mechanisms are tightly regulated by second messengersignalling pathways. Understanding of the relationship between calcium handling and contraction ('excitation-contraction coupling') has progressed from a mechanism in which activation of voltage-dependent calcium channels plays a central role (as in skeletal muscle) to a mechanism in which a small localized signalling event triggers a massive release of internal calcium (as in cardiac muscle) to a more complicated model in which the internal calcium pool divides the cytosol into two physiologically distinct spaces where the cytosolic concentration of calcium is regulated independently (as in vascular smooth muscle). The changes that may occur in calcium-handling pathways in asthma and the opportunities for novel approaches to the treatment of asthma are also discussed.

Key Words: Calcium channels, Excitation-contraction coupling, Ion channels, Sarcoplasmic reticulum

\section{Le métabolisme calcique dans le muscle lisse des voies aériennes : mécanismes et implica- tions thérapeutiques}

RÉSUMÉ: Le calcium joue un rôle de premier plan dans l'activation de nombreux processus cellulaires, y compris le point d'aboutissement le plus significatif dans la physiologie du muscle lisse : la contraction. Pour cette raison, la concentration cytosolique du calcium est étroitement régulée par un éventail complexe de mécanismes. Ces mécanismes comprennent de multiples voies d'entrée à partir du compartiment extracellulaire, une pompe située sur la membrane qui expulse le calcium de la cellule, une pompe interne qui séquestre le calcium dans un pool intracellulaire et au moins deux types de sites de libération d'où le calcium séquestré peut être remis en circulation dans le cytosol ; tous ces mécanismes sont étroitement régulés par des voies de signalisation médiées par des seconds messagers. Notre compréhension de la relation qui existe entre le métabolisme calcique et la contraction (couplage excitation-contraction) est partie d'un mécanisme dans lequel l'activation des canaux calciques voltage-dépendants joue un rôle clé (comme dans le muscle squelettique) pour arriver à un mécanisme dans lequel un petit signal localisé déclenche une libération massive de calcium interne (comme dans le muscle cardiaque) jusqu'à un modèle plus compliqué dans lequel le pool de calcium interne divise le cytosol en deux espaces physiologiques distincts où la concentration cytosolique de calcium est réglée indépendamment (comme dans le muscle lisse des vaisseaux). Les changements qui peuvent survenir dans le métabolisme calcique dans l'asthme et la possibilité d'approches novatrices en matière de traitement de l'asthme sont aussi discutés. 
$\mathrm{E}$ ver since Sydney Ringer realized his mistake in using tap water from the New River Water Company instead of using distilled water to identify the agent(s) responsible for ventricular shortening (1), it has become widely accepted that calcium plays an essential role in mediating muscle contraction. Moreover, it is now known that many other less easily discernible cellular events are also calcium dependent, including the activity of many enzymes and ion channels, cell growth and proliferation, and apoptosis. Thus, a thorough understanding of airway smooth muscle (ASM) physiology and pathophysiology must include the mechanisms underlying calcium concentration homeostasis.

\section{EXTRACELLULAR CALCIUM: INFLUX AND EXTRUSION}

In many cases, full activation of intracellular ASM enzymes occurs when the cytosolic concentration of calcium is elevated into the micromolar range $\left(10^{-6} \mathrm{M}\right)$, which is approximately 10 times higher than levels at rest. To some extent, this elevation involves entry of calcium from the extracellular space, where the concentration of calcium is in the millimolar range $\left(10^{-3} \mathrm{M}\right)$ (Figure 1). With calcium constantly entering the cell from such a vast extracellular pool, it is clear that the cell must also possess mechanisms whereby cytosolic calcium is ultimately extruded out of the cell to maintain the approximately 10,000-fold transmembrane concentration gradient for calcium. These various entry and extrusion pathways are described in more detail below.

Calcium influx: The lipid bilayer of the plasmalemma represents a nearly impassable barrier for the movement of charged ions and molecules into and out of the cell (electrical resistance greater than $1000 \mathrm{Ohm} \times \mathrm{cm}^{-2}$ ). However, ASM cells express many different polypeptide macromolecules that conduct external calcium into the cell in a controlled fashion.

Perhaps the most popular of these, recognized by experts and nonexperts alike, are the voltage-operated calcium channels (Figure 1). These calcium channels are made up of five subunits, only one of which (the alpha1 subunit) forms the

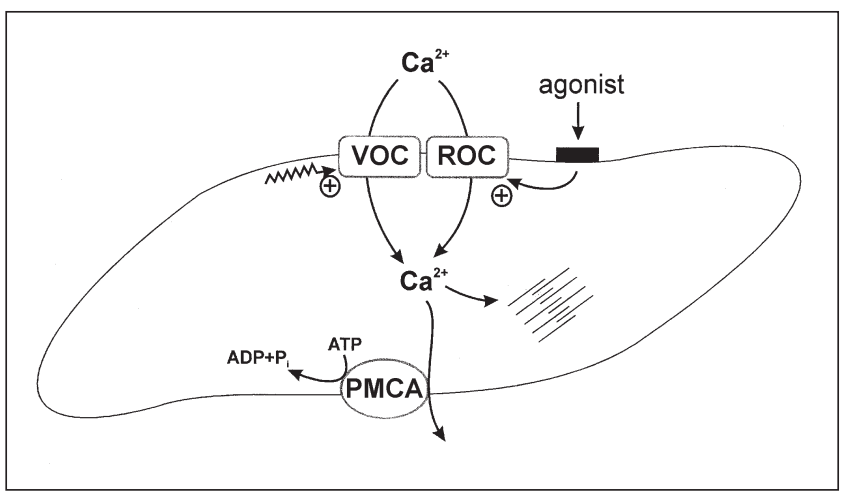

Figure 1) External calcium $\left(\mathrm{Ca}^{2+}\right)$ can enter the cell via voltageoperated and receptor-operated calcium channels. Once in the cytosol, calcium can activate the contractile apparatus (represented by parallel fibres) or be ejected by the plasmalemmal calcium pump (PMCA). ROC Receptor-operated channels; VOC voltageoperated channels actual channel pore while the others (alpha2, beta, gamma and delta) serve as regulatory proteins. As their name implies, these channels are able to sense the voltage gradient across the plasmalemma, ie, the membrane potential, and open when the membrane becomes depolarized above a certain critical threshold value (eg, in response to exposure to particular neurotransmitters or inflammatory mediators). Because the influx of cations causes membrane depolarization, the opening of even a few calcium channels in one part of the cell in the absence of a feedback inhibitory mechanism would initiate a positive feedback loop culminating in the sustained opening of all the calcium channels throughout the entire cell, with consequent calcium overload and cell death. To prevent this, channel activation is followed shortly (10 to $500 \mathrm{~ms}$ ) by another conformational change that limits calcium influx. This second change, referred to as 'inactivation' (not to be confused with channel closure or 'deactivation'), is also triggered by the membrane depolarization that caused channel opening but requires more time to occur. In addition, channel inactivation is triggered or enhanced in response to the elevation of the cytosolic calcium concentration at the cytosolic face of the channel. In other words, calcium influx precipitates a negative feedback inhibitory mechanism built into the channel itself. This way, membrane depolarization triggers only a transient and limited calcium influx.

ASM cells possess another type of calcium channel, the opening of which does not depend on membrane depolarization (although calcium may modify various aspects of channel function). These are referred to as nonselective cation channels (NSCs) because they discriminate among sodium, potassium and calcium poorly (2), in contrast to the calcium channels described above for which the calcium to sodium permeability ratio can be very high. NSCs are activated by a variety of spasmogens, including the major excitatory neurotransmitter acetylcholine (2), and, therefore, may be synonymous with 'receptor-operated' channels (Figure 1). Details of NSC activation are unclear but seem to involve G proteins and to be calcium independent $(3,4)$; thus, the transient activation of the muscarinic-signalling pathway may lead to transient calcium influx through NSCs as well as the voltage-operated calcium channels.

Calcium extrusion: Like many other cell types, ASM cells possess an ATP-driven calcium pump, the plasma membrane calcium ATPase (PMCA) that drives calcium out of the cell against the concentration gradient of calcium (Figure 1). There are four different genes that encode for PMCA, and each primary transcript from these genes can be alternatively spliced in eight different ways; this provides great diversity for PMCA with respect to structure and, therefore, function. In general, the final gene product is approximately 1100 to 1200 amino acids long (approximately 120 to $140 \mathrm{kD}$ ), with many phosphorylation sites for various protein kinases, allowing for the regulation of the pump by spasmogens and relaxants.

Skeletal, cardiac and some smooth muscle cells also express macromolecular complexes that translocate calcium out of the cell using the energy stored within the transmem- 
brane sodium gradient (which is built up by sodium/potassium ATPase activity). However, Janssen et al (5) have found that removing all external sodium - which instantaneously and completely inhibits sodium-calcium exchange has no effect on recovery from various forms of excitation, suggesting that sodium-calcium exchange plays no role in cytosolic calcium concentration homeostasis in ASM.

\section{THE EARLY VIEW OF EXCITATION-CONTRACTION COUPLING}

The sequence of events in which cell activation leads to a mechanical response - referred to as 'excitation-contraction coupling' - was first examined in skeletal and cardiac muscles. In these tissues, contraction results from activation of voltage-operated calcium channels initiated by an action potential (which was triggered by a motor neuron or by the sinoatrial node) (6). Later, the same was shown to be true for contraction in many vascular and gastrointestinal smooth muscles (7). Armed with this knowledge, researchers developed a variety of calcium channel blockers to reverse contraction and, thereby, treat clinical conditions in which the primary defect was excessive or inappropriate contraction, such as hypertension.

Initially, it was thought that the excitation-contraction coupling mechanism of skeletal and cardiac muscles was responsible for ASM contraction (Figure 1) and that respiratory disorders characterized by excessive bronchoconstriction could be treated using calcium channel blockers. Unfortunately, the latter had little or no effect on ASM tone, and, therefore, was useless in this respect. In fact, in vitro experiments using isolated airway tissues showed that contraction can occur in the absence of any change in membrane potential (8). To account for these findings, it was proposed that ASM (as well as many other smooth muscle tissues) possess a different class of calcium channels that are not gated by voltage - the receptor-operated channels $(8,9)$. However, contraction of isolated airway tissues in vitro can also persist temporarily in the complete absence of all external calcium but eventually disappears with repeated and/or continuous stimulation under these conditions, while reintroduction of calcium restores contraction. These findings indicated that, while contraction is ultimately calcium dependent, the immediate source of this calcium was not the extracellular space. It seemed that calcium was sequestered within some intracellular pool from which the cation could be liberated on agonist stimulation.

\section{INTERNAL CALCIUM: RELEASE AND UPTAKE}

Electronmicroscopic studies of airway and vascular smooth muscles showed that calcium can accumulate within intracellular organelles such as the endoplasmic reticulum and the mitochondrion (9). The present general consensus is that the physiologically relevant calcium pool through which agonists mediate their mechanical effects in muscle cells is located in the sarcoplasmic reticulum. The role of the mitochondrion in calcium handling during physiological conditions is unclear.

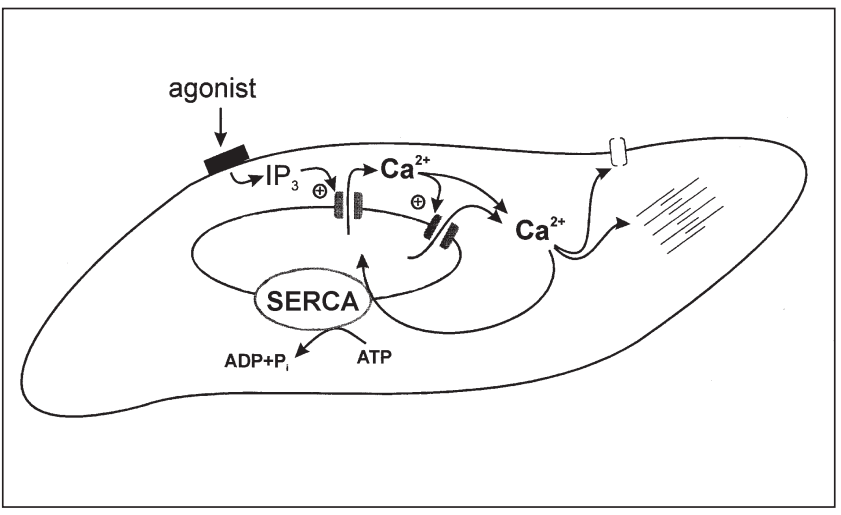

Figure 2) Spasmogens trigger inositol triphosphate $\left(I_{3}\right)$-induced calcium $\left(\mathrm{Ca}^{2+}\right)$ release, which in turn can initiate calciuminduced calcium release, as well as activation of plasmalemmal ion channels and the contractile apparatus. Calcium within the cytosol is taken back up via the sarcoplasmic reticulum calcium-ATPase (SERCA)

Release of internal calcium: Most, if not all, endogenous spasmogens (eg, neurotransmitters and inflammatory mediators) act through receptors that are coupled to phospholipase $\mathrm{C}$, an enzyme that metabolizes one of the lipids in the sarcolemma - phosphatidyl inositol phosphate - leading to the generation of the second messenger molecules diacylglycerol (activates protein kinase $\mathrm{C}$ ) and inositol trisphosphate (IP3). The latter opens calcium-permeable channels on the sarcoplasmic reticulum, thereby causing a transient elevation of the cytosolic calcium concentration, which in turn may trigger contraction and/or the activation of various ion channels (Figure 2).

There are three types of $\mathrm{IP}_{3}$-gated calcium channels. Each is a homotetramer (ie, made up of four identical subunits). The subunits are approximately 4000 amino acids each (approximately $300 \mathrm{kD}$ ) and form a quatrefoil-shaped particle (20 nm per side) with a $2 \mathrm{~nm}$ hole in the centre through which calcium can pass. The channels have phosphorylation sites for many kinases, allowing for tight regulation by endogenous agonists.

In addition to $\mathrm{IP}_{3}$-gated channels, the sarcoplasmic reticulum possesses calcium-permeable channels that open in response to an elevation of the cytosolic calcium concentration, a process referred to as calcium-induced calcium release (CICR) (Figure 2). In other words, spasmogen-triggered calcium release through $\mathrm{IP}_{3}$-gated channels is amplified through CICR; this is analogous to the mechanism underlying excitation-contraction coupling in cardiac muscles, in which a small influx of calcium through voltage-dependent calcium channels triggers a massive release of internally sequestered calcium through CICR. As pointed out above in the discussion of voltage-dependent calcium influx, CICR must be regulated by some form of feedback inhibition, otherwise the opening of just a few of these channels would lead to opening of all the CICR sites throughout the sarcoplasmic reticulum, resulting in complete depletion of the internal calcium pool and possibly in pathological consequences for ASM cells. The relationship that describes CICR channel activation and 
(A)

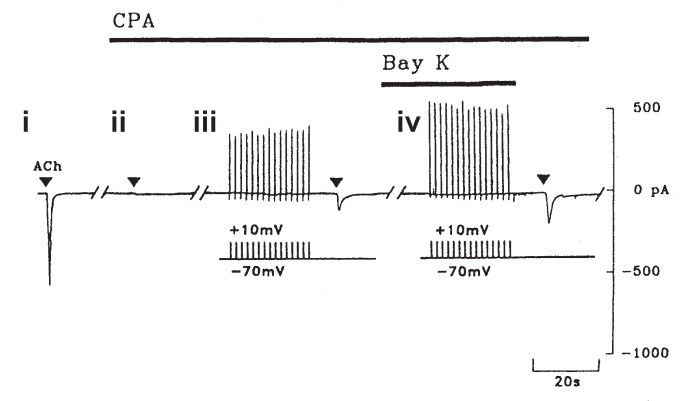

(B)

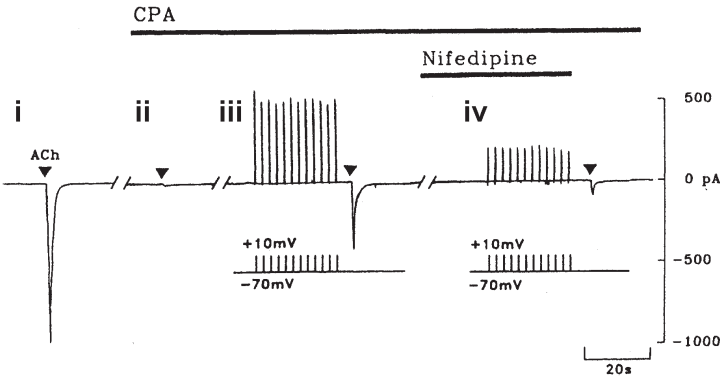

Figure 3) Two different airway smmoth muscle (ASM) cells (A and $B$ ) were studied under voltage-clamp conditions. (i) Acetylcholine (ACh) (indicated by shaded triangles) evokes inward currents that are triggered by release of internally sequestered calcium. (ii) Following repeated stimulation by ACh in the presence of the internal calcium pump inhibitor cyclopiazonic acid (CPA), the internal calcium pool becomes depleted, as indicated by loss of responsiveness to cholinergic stimulation. (iii) Voltage-dependent calcium channels are then activated by a series of depolarizing pulses (from $-70 \mathrm{mV}$ to $+10 \mathrm{mV}, 250 \mathrm{~ms}$ duration), after which the cholinergic response is partially restored, indicating partial refilling of the internal calcium store. (iv) This refilling is enhanced when the depolarizing pulses are delivered in the presence of BayK 8644 (which enhances voltage-dependent calcium currents), but reduced in the presence of the calcium channel blocker nifedipine. Data reproduced from reference (10)

the cytosolic concentration of calcium is bell-shaped with a peak at approximately $10^{-6} \mathrm{M}$, meaning that elevation of the cytosolic calcium concentration above $10^{-6} \mathrm{M}$ actually suppresses channel opening, thus limiting calcium efflux from the sarcoplasmic reticulum.

The CICR channels are also encoded by three different genes and are composed of four identical subunits of approximately 5000 amino acids ( 350 to $500 \mathrm{kD}$ ) with multiple phosphorylation sites for regulation by second messenger pathways. The channels can also be activated by caffeine, which enhances their sensitivity to calcium such that resting calcium levels are sufficient to induce opening. Ryanodine a plant-derived muscle-paralyzing alkaloid - binds to a high affinity site on CICR channels and induces channel opening; thus, these channels are also often referred to as ryanodine receptors. For decades, researchers in this field have wondered what the endogenous ligand that binds to CICR channels is (or why do ASM cells have a high affinity binding site for agents such as ryanodine or caffeine)? Cyclic ADP ribose - a metabolite of beta-NAD ${ }^{+}$, a common constituent of all cells was first shown to be the endogenous ligand for the 'ryanodine receptor' in sea urchin oocytes; more recently, cADP ribose has been shown to function the same way in skeletal and smooth muscles including ASM $(10,11)$.

Refilling and uptake of internal calcium: The store of calcium in the sarcoplasmic reticulum must be refilled after the calcium has been released. This is accomplished by a calcium pump on the sarcoplasmic reticulum membranes - the sarcoplasmic or endoplasmic reticulum calcium ATPase (SERCA) - that drives the translocation of cytosolic calcium into the sarcoplasmic reticulum using the energy liberated from ATP hydrolysis (Figure 2). Like PMCA, the SERCA pump maintains the cytosolic calcium concentration in the submicromolar range, while the concentration of calcium in the lumen of the sarcoplasmic reticulum rises into the millimolar range (ie, a 10,000-fold transmembrane concentration gradient). There are three isoforms of the $105 \mathrm{kD}$ SERCA protein - SERCA1, SERCA2 and SERCA3 - although at least two subtypes of SERCA2 (SERCA2a and SERCA2b) are known, the latter of which is found in most smooth muscles including ASM.

Studies in many nonexcitable cell types have shown that depletion of the internal calcium pool triggers opening of calcium-selective channels on the plasmalemma, thereby bringing calcium into the cell for refilling of the calcium pool; the depleted endoplasmic reticulum may release a factor that induces the calcium current, also referred to as a calcium release-activated current. An analogous situation is found in ASM; calcium released from the sarcoplasmic reticulum triggers calcium-dependent chloride and nonselective cation channels to open, leading to membrane depolarization and initiation of voltage-dependent calcium influx (as stated above, the nonselective cation channels themselves may also allow calcium into the cell). In other words, calcium release triggers calcium influx, which in turn can contribute to the refilling of the sarcoplasmic reticulum. Janssen and Sims (12) have provided direct evidence for this role of voltage-dependent calcium channels (Figure 3); in cells that were depleted of internal calcium (by repeatedly stimulating the cells with cholinergic agonist while simultaneously blocking SERCA-mediated reuptake), depolarizing pulses led to partial refilling of the internal calcium pool. Moreover, this refilling was reduced by voltage-dependent calcium channel blockers and was augmented by agents that enhance voltage-dependent calcium currents (Figure 3). Strangely enough, however, this refilling occurred while SERCA activity was blocked, suggesting some unusual and previously undescribed interaction between the voltagedependent calcium channels and the internal calcium pool; for example, calcium channels on the plasmalemma may somehow allow external calcium to enter the sarcoplasmic reticulum directly without first passing through the cytosol. The mechanisms underlying refilling of the internal calcium pool in ASM are still the focus of intensive research. 

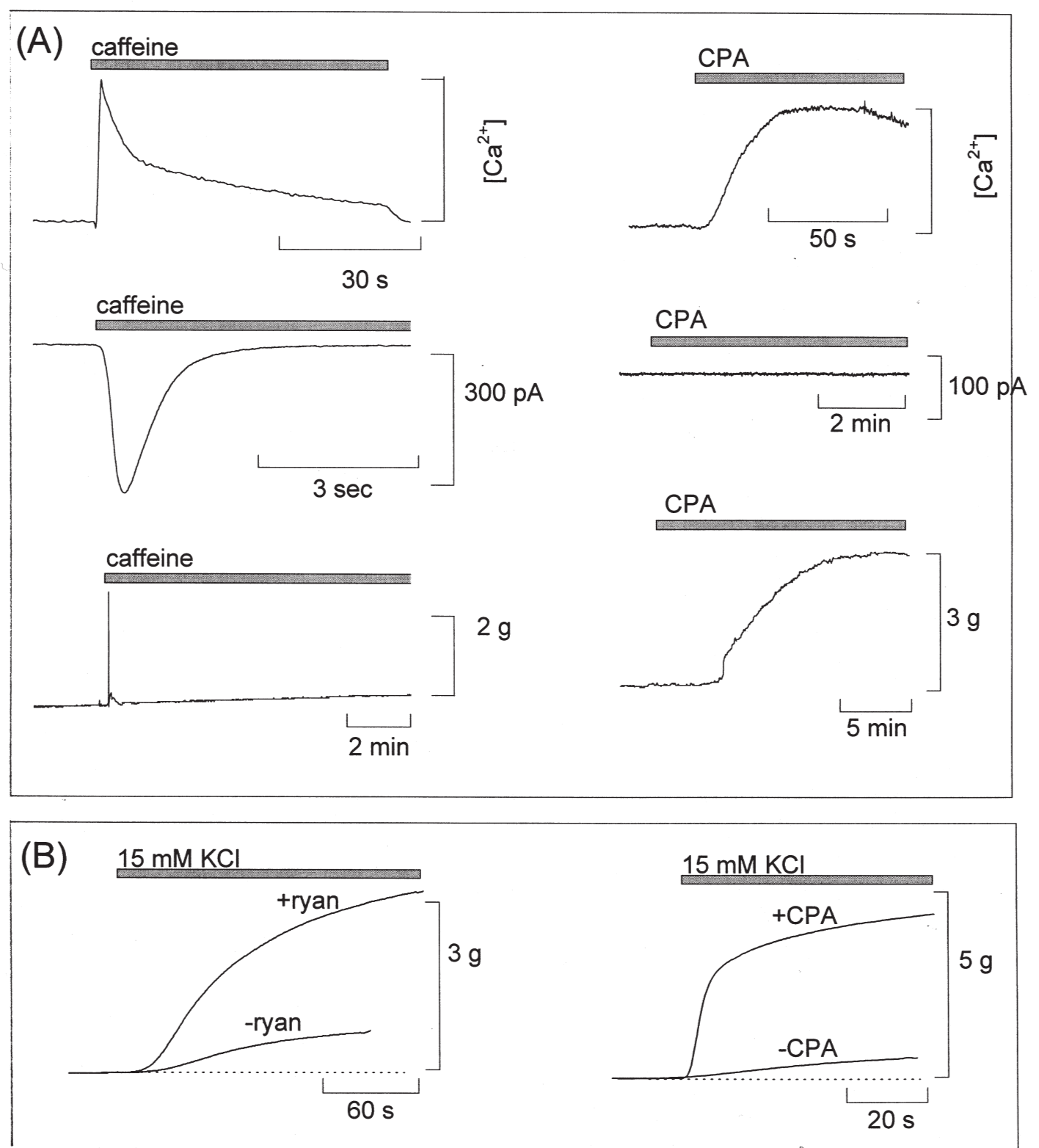

Figure 4) (A) The three panels on the left show the change in the concentration of calcium ([Ca $\left.\left.{ }^{2+}\right]\right)$, membrane current and contraction evoked by caffeine $(5 \mathrm{mM})$, while the three panels on the right show the corresponding responses to cyclopiazonic acid (CPA) (30 $\mu M)$. Note that while both caffeine and CPA elevate the cystolic concentration of calcium, caffeine activates ion channels with little or no contraction, while CPA activates the contractile machinery with little or no membrane current. (B) The contractile response to potassium chloride (KCl) (15 mM) was markedly potentiated by ryanodine $(30 \mu \mathrm{M})$ (left) or by $C P A(30 \mu \mathrm{M})$ (right).

\section{SUPERFICIAL BUFFER BARRIER AND VECTORIAL RELEASE}

Understanding of the role of the sarcoplasmic reticulum in regulating the concentration of calcium in the cytosol (Figure 2) was found to be much too simplistic; a more sophisticated model has been proposed for vascular smooth muscle (11), but it has not yet been tested in ASM. We found that agents that open calcium-gated calcium release channels (including caffeine and ryanodine) induce large membrane currents but are much less effective in evoking contraction
(Figure 4A, left panel), suggesting that concentration of calcium in the cytoplasm just underneath the membrane has been elevated but not that in the deep cytosol 14. On the other hand, an agent that inhibits SERCA activity triggers large contractions but little or no membrane current (Figure 4A, right panel), indicating the opposite changes in the calcium concentration in the cytosol. These findings are consistent with the hypothesis that the superficial sarcoplasmic reticulum separates the cytosol into two separate compartments - a subsarcolemmal compartment and a deep cytosolic compart- 


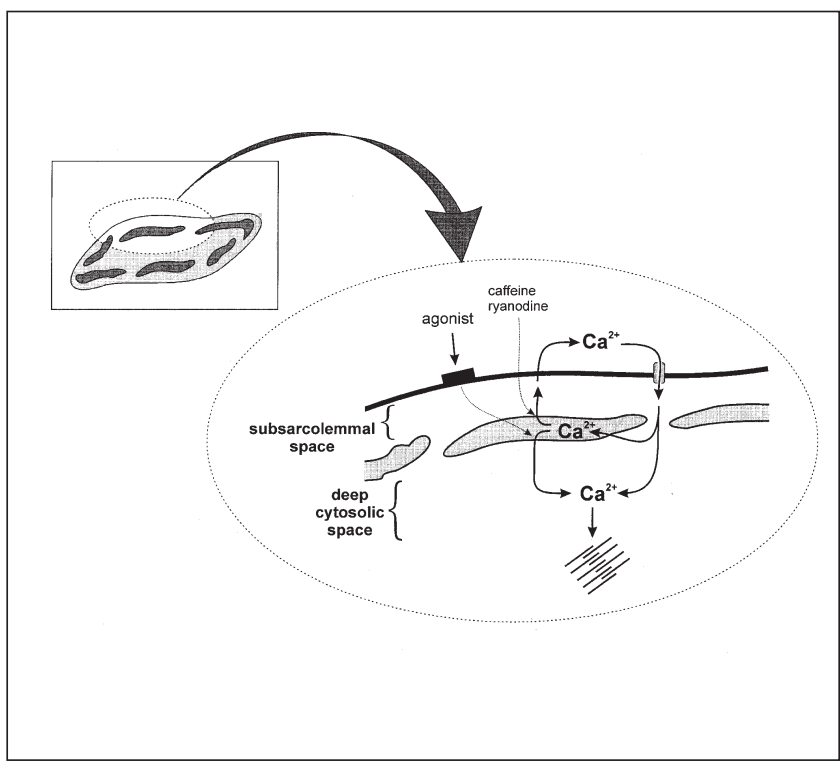

Figure 5) The sarcoplasmic reticulum forms parallel sheets just underneath the sarcolemmal, thereby dividing the cytosol into two distinct spaces: the subplasmalemmal space and the deep cytosolic space. This way, calcium $\left(\mathrm{Ca}^{2+}\right)$ release can be directed toward the plasmalemma for subsequent extrusion or to the deep cytosol in order to trigger contraction. Calcium entering across the sarcolemma immediately encounters this 'superficial buffer barrier', where it is either taken up (and diverted for extrusion) or allowed to pass through to the deep cytosol and activate the contractile apparatus

ment - in which the cytosolic calcium concentration can be regulated independently (Figure 5). According to this hypothesis, the sarcoplasmic reticulum can 'buffer' the elevation of the cytosolic calcium concentration caused by influx of external calcium and thereby modulate the resulting contraction; consistent with this, agents that compromised the buffering capacity of the sarcoplasmic reticulum were also found to potentiate markedly potassium chloride-evoked contractions (Figure 4B).

A corollary to the 'superficial buffer barrier hypothesis' is that calcium is preferentially directed by the sarcoplasmic reticulum toward the sarcolemma ('vectorial release') and then extruded from the cell by sodium-calcium exchange and/or the sarcolemmal pump, allowing the sarcoplasmic reticulum to continuously 'unload' without inducing contraction (Figure 5). This mechanism accounts for the finding that agents that activate the 'ryanodine-receptor' trigger membrane currents but not changes in tone.

This more sophisticated model allows for very complicated mechanisms of action for both spasmogens and bronchodilators. For example, it has been shown that spasmogens act by inducing calcium release and elevation of the cytosolic calcium concentration throughout the cell, leading to contraction as well as activation of calcium-dependent chloride and nonselective cation channels $(2,5,10)$; the resulting de-
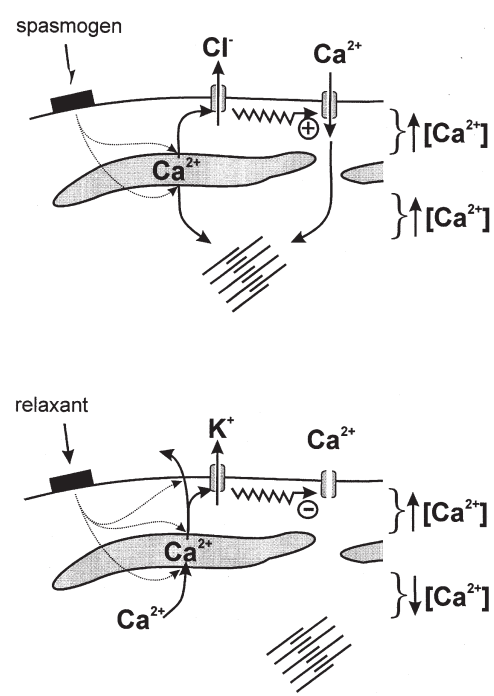

Figure 6) In airway smooth muscle, spasmogens release calcium $\left(\mathrm{Ca}^{2+}\right)$ into the deep cytosol, triggering contraction and into the subplasmalemmal space activating calcium-dependent chloride $\left(\mathrm{Cl}^{-}\right)$channels. The latter, in turn, causes membrane depolarization and voltage-dependent calcium influx, which prolongs or reinforces contraction and contributes to calcium-store refilling (above). Relaxants have been shown to elevate subplasmalemmal calcium concentration ( $\left.\left[\mathrm{Ca}^{2+}\right]\right)$ but decrease it in the deep cytosol, presumably via increased calcium pump activity and subsequent 'unloading' of calcium towards the sarcolemma. These changes in the cytosolic concentration of calcium lead directly to decreased contraction but possibly also to activation of calcium-dependent potassium $\left(\mathrm{K}^{+}\right)$channels with concomitant suppression of voltagedependent calcium channels (below)

polarization triggers voltage-dependent calcium influx, which prolongs and reinforces the contraction but also allows for refilling of the sarcoplasmic reticulum calcium pool (Figure 6, top). On the other hand, bronchodilators have been shown to elevate cytosolic calcium concentration in the subsarcolemmal space but decrease it in the deep cytosol (15), possibly through the simultaneous activation of the 'ryanodine-receptors' and SERCA. The results of these divergent changes are direct suppression of contraction and activation of calcium-dependent potassium channels, which hyperpolarize the membrane and suppress voltagedependent calcium influx (Figure 6, bottom), as was shown to be the case for vascular smooth muscle (16). The mechanisms by which spasmogens would selectively activate calcium-dependent chloride channels while bronchodilators would selectively activate calcium-dependent potassium channels are unclear, although both spasmogens and bronchodilators elevate calcium concentration in the subsarcolemmal space.

\section{THE CONVERGENT SIGNALLING PATHWAY} AND A NOVEL APPROACH TO TREATING ASTHMA

In asthma, the responsiveness of the ASM to cholinergic agonists, histamines, leukotrienes and adenosine is increased. This nonspecific nature of airway hyper-responsiveness sug- 
gests that a mechanism 'down-stream' from the receptors may be altered; one possibility includes calcium-handling mechanisms.

It is generally accepted that airway inflammation plays a central role in asthma. Inflammatory cells release reactive oxygen species and free radicals into the airways (eg, superoxide and hydroxyl anions), and these have been shown to alter calcium-handling in various cell types. For example, in endothelial, tracheal epithelial and cardiac muscle cells, free radicals increase the calcium permeability of the sarcolemma, leading to calcium overload and contracture (17-20). In the coronary artery, free radicals damage the sarcoplasmic reticulum calcium pump, resulting in a persistent calcium 'leak' and elevation of the calcium concentration in the cytosol (21). Recent studies using contractions as an indirect index of cytosolic calcium concentration have shown that airway hyperresponsiveness induced by ozone (another of the reactive oxygen species) may also involve a disruption of calcium-handling $(22,23)$. Inflammatory mediators can directly alter calcium-handling in ASM (24). However, comparisons of calcium-handling have not been made between asthmatics and nonasthmatics.

Whether calcium handling per se is altered in asthma, a greater understanding of calcium handling is nonetheless essential because Janssen and Sims (2) have shown that the spasmogens acetylcholine, histamine and substance $\mathrm{P}$ all mediate their effects through a convergent signalling pathway involving release of internally sequestered calcium via generation of $\mathrm{IP}_{3}$ (Figure 7). This knowledge raises the exciting possibility of a novel approach to reversing or preventing bronchoconstriction induced by any spasmogen (Figure 7).

\section{SUMMARY AND NEW DIRECTIONS}

Over the past few decades, the understanding of how calcium is handled and how it contributes to excitationcontraction coupling in ASM has been progressively refined and has become more sophisticated - from the primary role of voltage-dependent calcium influx (Figure 1) to the role of calcium release from internal stores (Figure 2) to the superficial buffer barrier and vectorial release of calcium (Figures 5 and 6). However, even the last model may need to be elaborated further to include a third cytosolic space, the perinuclear region, because many spasmogens also induce cell proliferation $(24,25)$. Some groups are beginning to examine periodic changes in nuclear calcium concentration (26).

Several specific questions are emerging as key areas of intense research. For example, the role of nonselective cation channels in mediating voltage-independent calcium influx and how this may relate to excitation-contraction coupling are being investigated, with the hope of somehow modulating this mediation of voltage-independent calcium influx to treat asthma, in the same way that classical calcium channel blockers are used to treat hypertension.

Also, the various implications of the superficial buffer barrier on ASM physiology and pathophysiology need to be examined. For example, the ionic 'switching' that seems to occur when the calcium concentration in the subplasmalem-

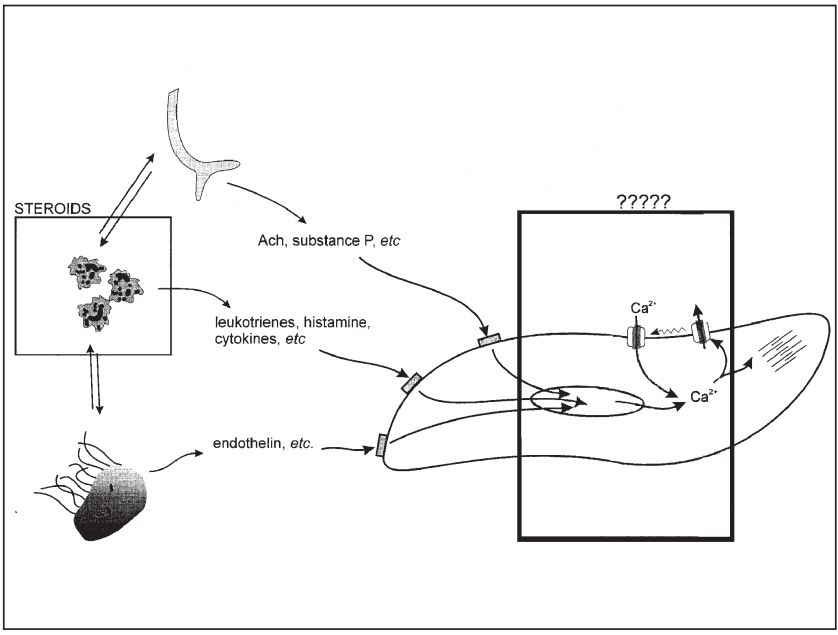

Figure 7) Bronchoconstriction is the product of the integrated input from agonists released by the innervation, inflammatory cells and the epithelium. In asthma, the airway smooth muscle exhibits increased sensitivity to a wide range of excitatory stimuli, and this is believed to be triggered or orchestrated by inflammatory cells. Because of this, steroids and leukotriene antagonists (indicated by the large shaded square) are now the treatment of choice for asthma. However, the nonspecific nature of airway hyperresponsiveness suggests that some postreceptor mechanism(s) within the smooth muscle per se is altered. Spasmogens act through a convergent signalling pathway involving calcium $\left(\mathrm{Ca}^{2+}\right)$ handling. A better understanding of the mechanisms underlying calcium handling and excitation-contraction coupling may lead to novel therapies for asthma (indicated by large shaded rectangle)

mal space is elevated by spasmogens (leading to activation of chloride channels) or by bronchodilators (leading to activation of potassium channels) needs to be examined. Also, free radicals (which play a major role in asthma) were shown to elevate cytosolic calcium concentration but to induce relaxation, a paradoxical finding that can now be explained using the superficial buffer barrier model. Another issue related to the model is the role of chloride channels and of chloride concentration in the refilling of the calcium pool. In ASM, spasmogens evoke large chloride currents and membrane depolarization, but the accompanying contraction is largely resistant to calcium or chloride channel blockers, raising questions as to why these channels are present. Recently, a chloride channel was isolated from ASM with properties diametrically opposite to those activated by spasmogens but similar to those on the sarcoplasmic reticulum membranes of skeletal and cardiac muscle and that facilitate calcium flux by neutralizing charge buildup on the sarcoplasmic reticulum membranes. It is possible that agonists activate chloride currents in ASM to facilitate calcium release or uptake. Consistent with this, Janssen and Sims (2) have previously noted anecdotally that ASM cells lose their ability to contract when the cytosolic concentration of chloride is reduced. In that study, the change in the cystolic concentration of chloride caused by acetylcholine was estimated be $3 \mathrm{mM}$ when assumed to be distributed uniformly throughout the entire cell. However, it is now known that the sarcoplasmic reticulum entraps a portion of the cytosol immediately underneath the 
membrane (Figure 5), the volume of which is approximately $0.1 \%$ of the overall cell volume. Thus, the change in the cytosolic concentration of chloride at the periphery of the cell may be much more profound than previously thought. Also, the role of cADP ribose in the physiological (and possibly in

\section{REFERENCES}

1. Ringer, S. A further contribution regarding the influence of the different constituents of the blood on the contraction of the heart. J Physiol 1883;4:29-42.

2. Janssen LJ, Sims SM. ACh activates non-selective cation and chloride conductances in canine and guinea-pig tracheal myocytes. J Physiol (Lond) 1992;453:197-218.

3. Fleischmann BK, Wang YX, Kotlikoff MI. Muscarinic activation and calcium permeation of nonselective cation currents in airway myocytes. Am J Physiol 1997;272:C341-9.

4. Wang Y-X, Fleischmann BK, Kotlikoff MI. $\mathrm{M}_{2}$ receptor activation of nonselective cation channels in smooth muscle cells: calcium and $\mathrm{G}_{\mathrm{i}} / \mathrm{G}_{\mathrm{o}}$ requirements. Am J Physiol 1997;273:C500-8.

5. Janssen LJ, Walters DK, Wattie J. Regulation of $\left[\mathrm{Ca}^{2+}\right]_{i}$ in canine airway smooth muscle by $\mathrm{Ca}^{2+}$-ATPase and $\mathrm{Na}^{+} / \mathrm{Ca}^{2+}$ exchange mechanisms. Am J Physiol 1997;273:L322-30.

6. Katz B. Nerve, Muscle, and Synapse. New York: McGraw-Hill, 1996:1-167.

7. Horowitz A, Menice CB, Laporte R, Morgan KG. Mechanisms of smooth muscle contraction. Physiol Rev 1996;76:967-1003.

8. Bolton TB, Large WA. Are junction potentials essential? Dual mechanism of smooth muscle cell activation by transmitter released from autonomic nerves. Q J Exp Physiol 1986;71:1-28.

9. Bolton TB. Mechanisms of action of transmitter and other substances on smooth muscle. Physiol Rev 1979;59:606-718.

10. Kannan MS, Fenton AM, Prakash YS, Sieck GC. Cyclic ADP-ribose stimulates sarcoplasmic reticulum calcium release in porcine coronary artery smooth muscle. Am J Physiol 1996;270:H801-6.

11. Prakash YS, Kannan MS, Walseth TF, Sieck GC. Role of cyclic ADP-ribose in the regulation of $\left[\mathrm{Ca}^{2+}\right]_{i}$ in porcine tracheal smooth muscle. Am J Physiol 1998;274:C1653-60.

12. Janssen LJ, Sims SM. Emptying and refilling of $\mathrm{Ca}^{2+}$ store in tracheal myocytes as indicated by ACh-evoked currents and contraction. Am J Physiol 1993;265:C877-86.

13. van Breemen C, Chen Q, Laher I. Superficial buffer barrier function of smooth muscle sarcoplasmic reticulum. Trends Pharmacol Sci 1995;16:98-105.

14. Janssen LJ, P Betti. Mebrane currents, $\left[\mathrm{Ca}^{2+}\right]$-transients and contractions indicate a superficial buffer barrier in canine airway smooth muscle. Biophys J 1998;74:A258 the pathophysiological) regulation of the internal calcium pool needs to be elucidated.

Finally, investigations into changes in the mechanisms underlying calcium handling in ASM during asthma and airway hyperresponsiveness are of paramount importance.

15. Yamaguchi H, Kajita J, Madison JM. Isoproterenol increases peripheral $\left[\mathrm{Ca}^{2+}\right]_{\mathrm{i}}$ and decreases inner $\left[\mathrm{Ca}^{2+}\right]_{\mathrm{i}}$ in single airway smooth muscle cells. Am J Physiol 1995;268:C771-9.

16. Nelson MT, Cheng H, Rubart M, et al. Relaxation of arterial smooth muscle by calcium sparks. Science 1995;270:633-7.

17. Franceschi D, Graham D, Sarasua M, Zollinger RM Jr. Mechanisms of oxygen free radical-induced calcium overload in endothelial cells. Surgery 1990;108:292-7.

18. Josephson RA, Silverman HS, Lakatta EG, Stern MD, Zweier JL. Study of the mechanisms of hydrogen peroxide and hydroxyl free radical-induced cellular injury and calcium overload in cardiac myocytes. J Biol Chem 1991;266:2354-61.

19. Clague JR, Langer GA. The pathogenesis of free radical-induced calcium leak in cultured rat cardiomyocytes. J Mol Cell Cardiol 1994;26:11-21.

20. Qu QS, Chen LC. Modulation of $\mathrm{Ca}^{2+}$ influx by a mediator released from human tracheal epithelial cells exposed to ozone in vitro. Am J Physiol 1995;268:L558-64.

21. Grover AK, Samson SE, Fomin VP, Werstiuk ES. Effects of peroxide and superoxide on coronary artery: ANG II response and sarcoplasmic reticulum $\mathrm{Ca}^{2+}$ pump. Am J Physiol 1995;269:C546-53.

22. Montaño L, Jones GL, O'Byrne PM, Daniel EE. Effect of ozone exposure in vivg on response of bronchial rings in vitro: role of intracellular $\mathrm{Ca}^{2+}$. Am J Physiol 1993;75:1315-22.

23. Roux E, Guibert C, Crevel H, Savineau JP, Marthan R. Human and rat airway smooth muscle responsiveness after ozone exposure in vitro. Am J Physiol 1996;271:L631-6.

24. Amrani Y, Panettieri RA Jr, Frossard N, Bronner C. Activation of the TNF alpha-p55 receptor induces myocyte proliferation and modulates agonist-evoked calcium transients in cultured human tracheal smooth muscle cells. Am J Respir Cell Mol Biol 1996;15:55-63.

25. De S, Zelazny ET, Souhrada JF, Souhrada M. Role of phospholipase C and tyrosine kinase systems in growth response of human airway smooth muscle cells. Am J Physiol 1996;270:L795-802.

26. Bkaily G, Pothier P, D'Orleans-Juste P, et al. The use of confocal microscopy in the investigation of cell structure and function in the heart, vascular endothelium and smooth muscle cells. Mol Cell Biochem 1997;172:171-94. 


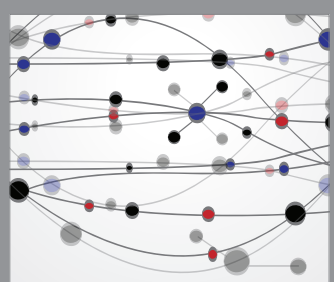

The Scientific World Journal
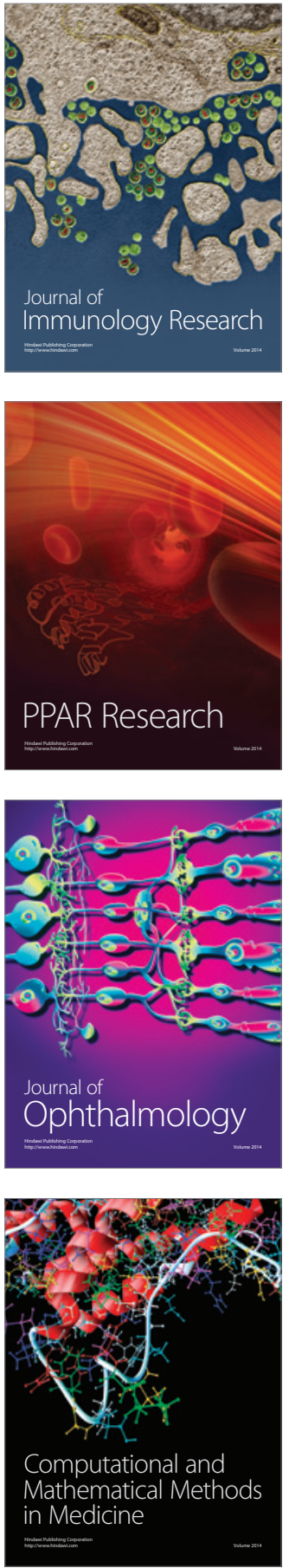

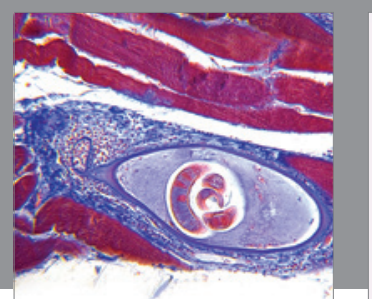

Gastroenterology Research and Practice

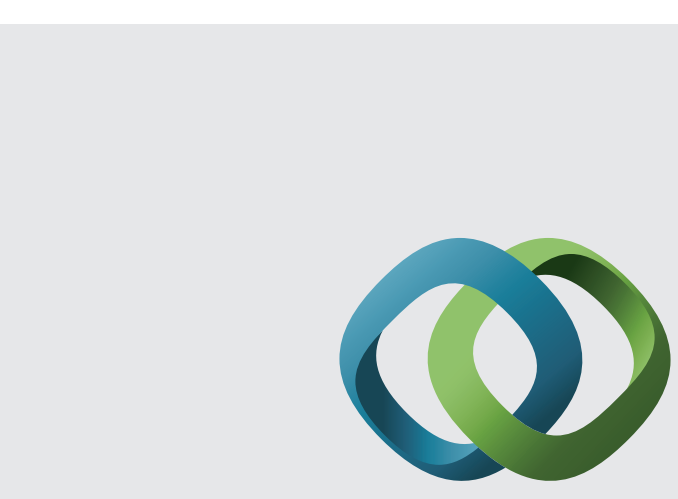

\section{Hindawi}

Submit your manuscripts at

http://www.hindawi.com
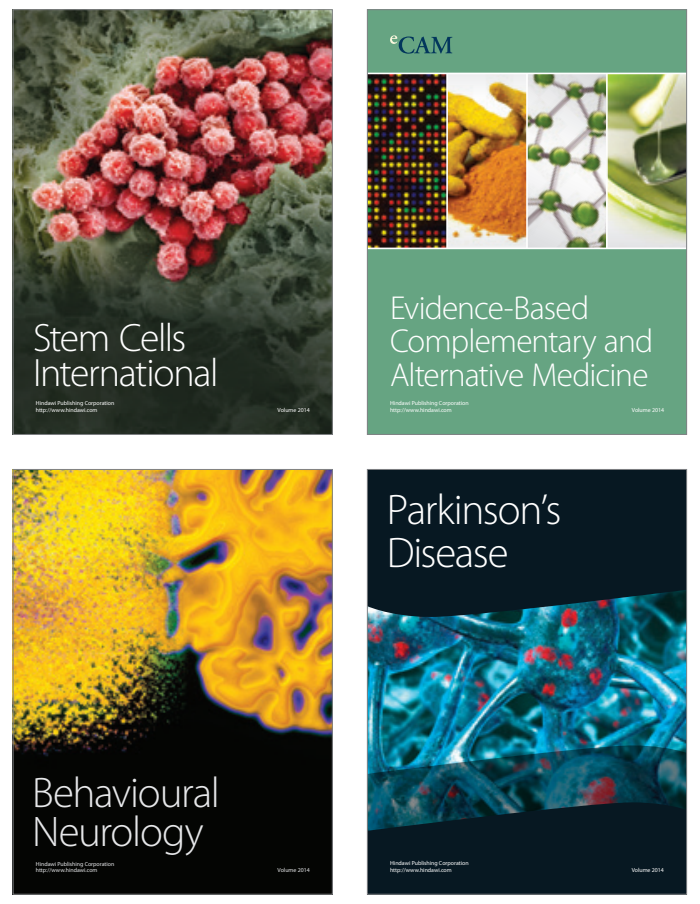
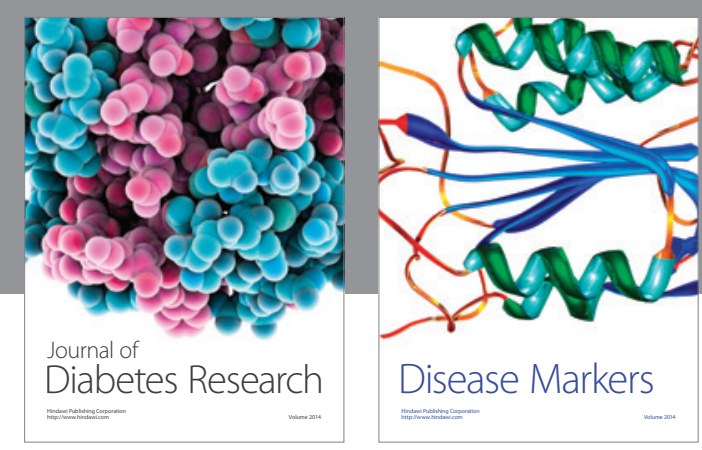

Disease Markers
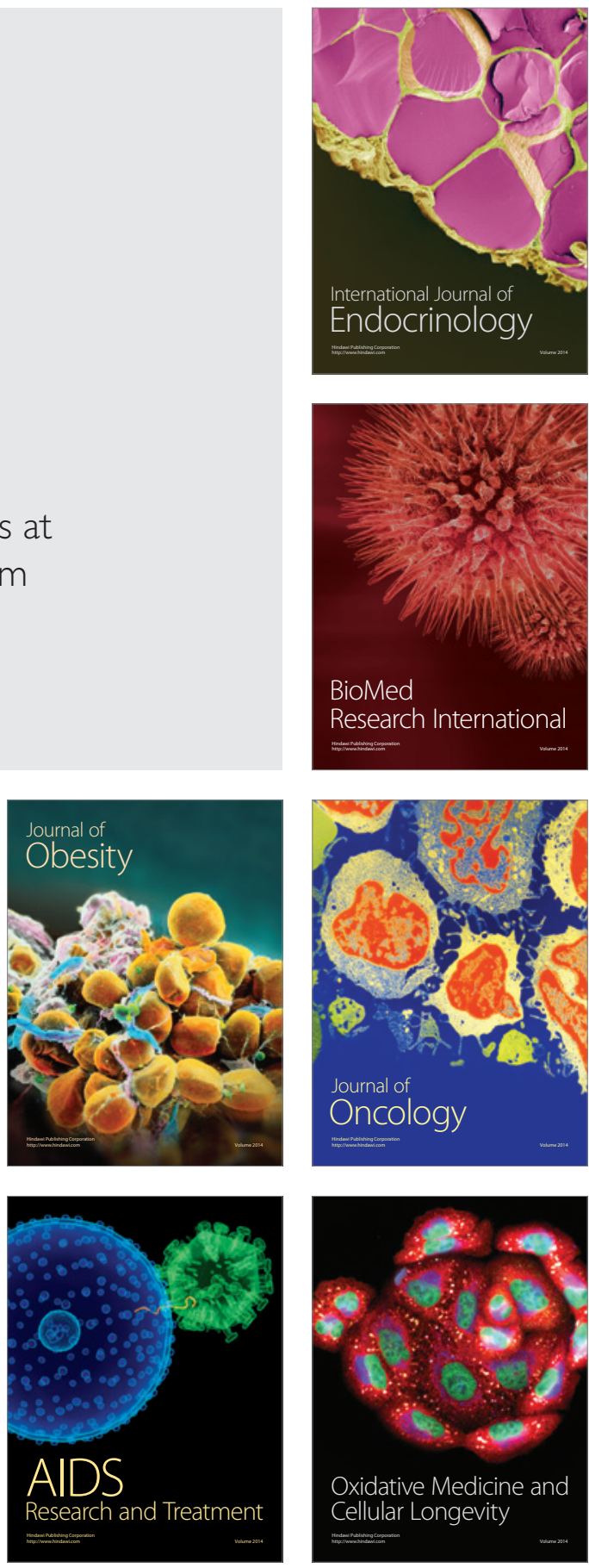